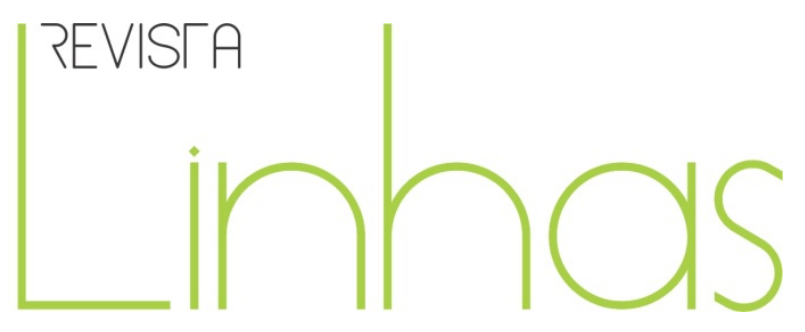

\title{
Resenha do livro Os herdeiros: os estudantes e a cultura
}

BOURDIEU, Pierre; PASSERON, Jean-Claude. Os Herdeiros: os estudantes e a cultura. Trad. Ione Ribeiro Valle e Nilton Valle. Florianópolis: Editora da UFSC, 2014.

\section{Tiago Ribeiro Santos}

Doutorando no Programa de Pós-graduação em Educação da Universidade Federal de Santa Catarina - UFSC - Brasil

tiago.ribeiro@live.com

\section{Silvana Rodrigues de Souza Sato}

Doutoranda no Programa de Pós-graduação em Educação da Universidade Federal de Santa Catarina - UFSC - Brasil

sil.sato@uol.com.br

\section{Melina Kerber Klitzke}

Graduada no Curso de Pedagogia da Universidade Federal de Santa Catarina - UFSC Brasil

melinaklitzke@hotmail.com

\section{Para citar esta resenha:}

SANTOS, Tiago Ribeiro; SATO, Silvana Rodrigues de Souza; KLITZKE, Melina Kerber. Resenha do livro Os herdeiros: os estudantes e a cultura. Revista Linhas. Florianópolis, v. 15, n. 29, p. 341-348, jul./dez. 2014.

DOI: $10.5965 / 1984723815292014341$

http://dx.doi.org/10.5965/1984723815292014341 
Respira-se melhor quando se é rico; é-se mais livre quando se é célebre; o próprio ter de um título de nobreza é um pequeno monte. Tudo é artifício, mas o artifício nem sequer é nosso. Subimos a ele, ou levaramnos até ele, ou nascemos na casa do monte.

Fernando Pessoa

Os Herdeiros, obra de Pierre Bourdieu (1930-2002) e Jean-Claude Passeron (1930-) completa em 2014 cinquenta anos desde sua primeira publicação na França. O livro chega agora ao Brasil vertido para o português pelas mãos de lone Ribeiro Valle e Nilton Valle, ambos também responsáveis pela tradução de Homo Academicus de Bourdieu, publicado pela Editora da UFSC em 2011. Os Herdeiros oportuniza novas aberturas para interrogações acerca do campo educacional brasileiro, coloca em questão principalmente: o papel do sistema escolar para a reprodução social; a ideia de igualdade de oportunidades de acesso à universidade; a ideologia meritocrática; e a real democratização da educação. O leitor possivelmente observará o alargamento das discussões que enfatizam a relação da escola com a democratização da cultura, lançando desafios maiores sobre o nosso tempo, e que serão apresentados a seguir.

Os Herdeiros: os estudantes e a cultura, publicado em 1964 no contexto de grandes reformas no sistema de ensino francês lança "areia na máquina" ao desestabilizar a ideia, filha do esclarecimento, de a escola ser democrática, promotora de mobilidade social - em suma - libertadora. O sistema de ensino universitário e sua relação com uma elite cultural distinta é o mote do debate que atravessa o livro, acendendo outra fagulha de crítica sobre a conservação escolar de desigualdades sociais. Os autores, calcados por enquetes, entrevistas e massivas informações estatísticas, identificam que a origem social é um dos mais determinantes fatores tanto para o sucesso quanto para o fracasso escolar. O filho ou filha de assalariado agrícola, operário, profissional liberal serve, assim, como uma variável que exerce peso sobre o prolongamento da escolaridade, assim como na possível escolha do curso universitário. A 
obra fere, então, o orgulho da democracia francesa que confiava ao sistema de ensino não apenas a promoção da mobilidade social, mas também a representação de instituições que distinguem, com justiça, o mérito de cada estudante. Os supostos méritos e dons que autorizam a ascensão escolar dos discentes são colocados então em desconfiança quando fatores como a categoria socioprofissional dos pais são identificados como determinantes no ingresso à universidade; e as exceções à regra - os estudantes ingressantes de origem familiar desfavorecida - tão somente reforçam a ilusão democrática tracionada pela universidade, sendo inibidos de criticar o sistema que favorece suas posições.

Os Herdeiros pode ser lido, logo, como análise não somente do elitismo do público universitário de sua época, a partir de uma relação fortemente amigável entre a cultura universitário-escolar e a cultura erudita; também como análise da socialização que organiza condutas e sentidos, perpetuando a ordem social. O processo de construção da crença no sistema de ensino não pode ser efetivado sem a cumplicidade de estudantes e professores que incorporam tacitamente $a$ universidade - o que não custa lembrar: o lugar supostamente mais prestigioso em matéria de educação, de agentes que pensam e pensarão sobre a educação, o trabalho, o mundo, em suma, que ocuparão cargos supostamente dirigentes. O sistema de ensino, assim sendo, reproduz desigualdades sociais em benefício das relações estabelecidas na escola entre intelectuais (os professores) e os estudantes vindos de classes econômica e culturalmente distintas e favorecidas. Daí a denúncia de uma “aristocracia social” conservada pela escola.

O primeiro capítulo, A escolha dos eleitos, examina as chances de acesso à universidade a partir de variáveis como origem social, sexo e gostos artísticos. Os gráficos distribuídos ao longo das páginas apontam numérica e percentualmente que as chances de acesso são gritantemente desiguais no tocante ao período de 1961-1962. Os estudantes vindos de famílias de profissionais liberais e quadros superiores contam com $58,5 \%$ de chances de acesso em relação aos $0,7 \%$ daqueles originários de famílias de assalariados agrícolas. Os eleitos são, portanto, escolhidos desde cedo. A categoria socioprofissional dos pais, por exemplo, fortemente tendendo a determinar o ingresso na universidade, retrai a ideia de que o sistema de ensino promove a igualdade social. 
Os eleitos não são apenas escolhidos, eles também escolhem: a eliminação escolar de moças oriundas de classes populares dá lugar à restrição das escolhas e ao direcionamento implícito da carreira. É quando a estudante que ingressa no curso de Letras, por exemplo, vivendo a graduação como vocação ou com ares de espontaneidade, mantém impensado o processo de socialização familiar responsável em orientar as aspirações individuais e que a conduz para postos sociais de baixo prestígio.

O sexo é outro marcador determinante na produção e conservação da cultura e consequentemente das desigualdades sociais; é quando as moças nos cursos de vocação incerta tendem a provar os sabores de uma aventura intelectual: o destino social é sentido como resultado de ações realizadas ao longo do curso. O sentimento de responsabilidade pelo sucesso ou fracasso, aí, se intensifica: porque os movimentos do jogo, cada cartada, necessitam das mulheres a seriedade, disciplina, docilidade, em suma, autovigilâncias que atuam conformando o corpo ao espaço universitário predominantemente masculino na década de 1960. O que se vê é a distância entre a objetividade (das posições) e a subjetividade (dos agentes) implicando não apenas aflições e experiências dolorosas para os estudantes menos favorecidos, mas, ocasionalmente, também ascensões que geram sentimentos de gratidão à universidade.

Os eleitos são, portanto, também aqueles que escapando da eliminação provável elegem a universidade como responsável pelas suas ascensões causais e conservadoras o que é um paradoxo. O contexto brasileiro não teria, aí, algo a dizer sobre a formação à jato de estudantes que vivem a universidade, em linha reta da graduação ao doutoramento, sem querer deixá-la porque sentem dever a ela o que vivem, principalmente quando a instituição se torna a única via de acesso e compartilhamento da cultura nela adquirida? Que democratização é essa? Os Herdeiros estimula, assim, interrogações sobre as razões do prolongamento dos estudos quando a universidade acolhe temporariamente aqueles que - também por fazerem valer o sentimento de dádiva recebida - resistem à entrada no mundo do trabalho.

O segundo capítulo, Jogos sérios e jogos de seriedade, avança contornando as práticas de estudantes e professores que conferem crença à universidade; e nuança sem citar diretamente a noção de interesse ou illusio que mais tarde marcará a obra de 
Bourdieu. Quem investe no jogo universitário crê, essencialmente, que vale a pena jogar. Os herdeiros - sobretudo os "diletantes" - investindo interesse no jogo universitário, sem reafirmar propriamente sua importância, desfrutam da experiência de conhecer o mundo pelos deslumbramentos científicos e eruditos. O conhecimento ou o prazer em conhecer se apresenta assim aos grupos culturalmente privilegiados mais como necessidade que utilidade, definindo estilos de vida. Os gostos pela cultura livre, fruição, pela aventura da descoberta motivada pelo saber, sendo socialmente herdados pela origem familiar dos estudantes, são recompensados pelo diploma universitário: carta de entrada no mundo também sério do trabalho - de aparência austera porque medido pelos conhecimentos que a universidade conserva na forma de conquistas históricas da humanidade.

A universidade, logo, passagem obrigatória não percebida como obrigação, rentabiliza o privilégio cultural herdado. Os agenciamentos, para tanto, se organizam tacitamente, na viscosidade das relações, entre os estudantes herdeiros e os professores integrados à universidade, suspendendo a racionalidade econômica, o cálculo premeditado de resultados. O estudante universitário, qualquer que seja, está disposto a preferir, principalmente devido às afinidades culturais, senão alguns ao menos um professor exemplar: o verdadeiro mestre, imagem maravilhada e reconhecida de virtuosidades que representam o meio acadêmico. O carisma do e pelo mestre, confiança na natureza intangível do dom, conserva não apenas o encanto do estudante pela universidade; também a organização dos interesses subjetivos em conformidade às posições objetivas, pois, para se tornar filósofo é preciso inicialmente um diploma de filosofia.

O tipo ideal de estudante universitário francês, separado do mundo do trabalho, dispõe de tempo livre para assumir suas próprias atividades, ou seja, sem a necessidade de ser controlado pelos pais ou professores: porque ele é o principal responsável pela sua formação. O cinema de domingo pode ser trocado pelo de segunda-feira e mais perfeitamente ainda quando o universitário dispõe de companhias na mesma condição, favorecendo a produção do sentimento de grupo, l'esprit de corps, reforçando afinidades, em suma, integrando interesses sem exigir a reflexividade, e em contrapartida, 
economizando raciocínios ao passo que assumir uma rotina sem rotinas se torna uma disposição duradoura. O universitário está sujeito, assim, pela liberdade que é Ihe concedida, seja parisiense ou provinciano, à deliciosa sensação de se sentir autêntico; alguém que exerce sobre si um trabalho que nenhum outro poderia fazer em seu lugar. 0 aluno de ensino superior e de origem parisiense, entretanto, se difere do provinciano que está menos disposto à auto-organização; seria então o habitus de estudante se apresentando geograficamente variável? Quiçá, sim, ainda que habitus, capital cultural, violência simbólica, poder simbólico, conceitos que aparecerão mais claramente em $A$ Reprodução (1970), não estejam presentes em Os Herdeiros.

Os estudantes universitários culturalmente desfavorecidos em nada estão privados da satisfação das conquistas. O diploma obtido, o curso de pós-graduação ingressado, o seminário exaustivo concluído etc. são pontos de chegada, geralmente marcados pelas comemorações, que tornam cada vez mais provável um futuro não apenas rentável, também aos desfavorecidos, um futuro supostamente favorável. Os estudantes autorizados a sonhar com o futuro pelas certificações que recebem estão sujeitos, entretanto, ao infortúnio invisível de serem qualificados pelos desqualificados os professores se relacionalmente situados - herdando posições desprestigiadas de um espaço prestigioso, sendo enfim o "contrabaixo da orquestra". O carisma novamente se impõe aqui e mais eficazmente à medida que mantém inobservadas entre estudantes e professores suas próprias carências objetivas - como pode ser atualmente - a ausência de publicação em periódicos de impacto.

O sentido encantado das experiências estudantis segue arrematado no terceiro e último capítulo, Aprendizes ou aprendizes de feiticeiros? O estudante ideal se produz como alguém capaz de produzir cultura; envolvido com os caldeirões da academia, cria e recria o saber. Os estudos dos aprendizes em laboratório prosperam ao passo que o divertimento aí ocasionado - o divertere, o desvio - suspende a preocupação com o futuro profissional. Os autores, investidos sensivelmente da ideia de instituição, conferem assim à universidade a capacidade de organizar e orquestrar sentidos - numa expressão tão cara à sociologia - de socializar os agentes para integrá-los ao conjunto de normas e transformá-las em personalidades. 
Cabe ressaltar que o mundo social burguês de caráter individualista é composto de instituições, dentre elas a escola, que perpetuam e legitimam as promessas da modernidade. Apesar da ação homogeneizante da escola e da, na maioria das vezes, falsa preconização de um trabalho coletivo, o ideal escolar é o da competição. Por exemplo, a escrita acadêmica entre dois, três ou mais autores pode incentivar o trabalho dissertativo e de pesquisa em conjunto, mas também pode dissimular a busca por maior número de publicações solicitadas por diferentes agências de aperfeiçoamento e desenvolvimento científico.

Os autores revelam que a lógica do sistema deixa na obscuridade as desigualdades sociais e a escola trata estas desigualdades como naturais, denominadas como dons e méritos individuais. Compreendem "que esse sistema encontra sua plena realização no concurso, que assegura perfeitamente a igualdade formal dos candidatos, mas que exclui pelo anonimato as desigualdades reais diante da cultura" (p. 92). É nos momentos de exames/provas que a influência da origem social pesa com toda sua força ocultando a suposta igualdade formal entre os estudantes. A universidade exige que todos os que pretendem acessá-la façam parte de um jogo no qual as regras da competição seguem apenas critérios escolares - hierarquia escolar das performances. Nada mais conveniente ao sistema que busca a produção de agentes selecionados e comparáveis.

A defesa de uma ação pedagógica racional é enfatizada no terceiro capítulo e na conclusão da obra, demonstrando que não apenas os resultados dos exames deveriam ser levados em conta, mas, também o ponto de partida dos candidatos. O argumento é favorável a um trabalho mais criterioso e reflexivo por parte dos docentes. Reiterando as palavras dos autores, a pedagogia racional envolve um "professor de qualidade para alunos de qualidade" (2014, p. 99), e estes últimos apreendendo as exigências de uma verdadeira e significativa aprendizagem.

As políticas escolares que favorecem o acesso ao ensino superior são lembradas, mas com elas a importância da diminuição das desigualdades sociais, para que as mesmas não caiam apenas em formalidades. O cenário educacional brasileiro, principalmente após a Lei de Diretrizes e Bases da Educação Nacional (LDB no. 9.394/1996), tem sido marcado 
por políticas de incentivo ao prolongamento da escolarização que tentam neutralizar déficits sociais como a origem familiar economicamente frágil. Os Herdeiros lembra, entretanto, que as condições do sucesso escolar não são somente econômicas, mas também culturais.

Recebido em: 30/11/2013 Aprovado em: 21/02/2014

Universidade do Estado de Santa Catarina - UDESC Programa de Pós-Graduação em Educação - PPGE Revista Linhas Volume 15 - Número 29 - Ano 2014 revistalinhas@gmail.com 